\title{
REVIEW ON DEVELOPMENT OF CERAMIC MEMBRANE FROM SOL- GEL ROUTE: PARAMETERS AFFECTING CHARACTERISTICS OF THE MEMBRANE
}

\author{
M. R. Othman and H. Mukhtar \\ School of Chemical Engineering, Universiti Sains Malaysia, Perak Branch Campus, 31750 Tronoh, Perak, \\ Malaysia.
}

\begin{abstract}
The importance of laboratory scale ceramic membrane preparation using sol-gel technique with pore sizes in the range of $1-10 \mathrm{~nm}$ is reviewed. Parameters affecting the characteristics of membrane during membrane development are highlighted and discussed in detail. Experimental results from literatures have shown that the correct amount of acid, water, PVA, appropriate membrane thickness, proper control of drying rate, and appropriate temperature profile selection during sintering process are necessary in order to acquire sufficient strength and reduce the formation of crack in the membrane. The different temperature setting during sintering process also influences the size of pore formed.
\end{abstract}

Key Words: Sol-Gel, Inorganic Membrane, Ceramic Membrane, Gas Permeation, Sintering, Sol Properties, Membrane Morphologies, Pore Size Distribution.

\section{INTRODUCTION}

Ceramic membranes have played an important role in the fields such as particulate filtration, gas separation and analytical application (sensors for gases and chemicals). For alumina membranes in particular, they have made a successful entry into the market as in line gas filters. In microelectronic packaging, food and pharmaceutical industries where clean air is required, removal of fine particles from gas streams can be achieved by means of porous ceramic membranes. The reasons they are selected are due to the following aspects, ${ }^{[1]}$

- They are thermally stable and chemically inert in the application environment.

- The rigid ceramic media does not introduce particles into the gas stream by shedding under harsh conditions of flow pulsation and mechanical vibration or shocks.

- They do not react with the process gases or generate impurities nor produce hydrogen outgassing problem

- Their pore size distributions are narrow and can retain an extremely high percentage of particulates

- They can be easily regenerated periodically by backflushing when membrane fouling occurs

- They can be steam sterilized without changing their microstructure and chemical characteristics.
This paper reviews the preparation of ceramic membranes using sol-gel technique to produce membrane having pore sizes between 1 and 10nm. Parameters influencing the production of ceramic membranes with desirable characteristics are also highlighted.

\section{CERAMIC MEMBRANE PREPARATION}

Laboratory scale ceramic membranes can be prepared by hydrolizing metal-organic compounds or alkoxides such as aluminium secondary butoxide with water to produce sol. Peptization of the sol using acid at temperature of about $90^{\circ} \mathrm{C}$ under rigorous stirring condition is ensued to prevent precipitation. The peptized (stable) sol is then cooled down steadily to allow formation of gel. Later, the gel is fired (sintered) to obtain the oxide product (refer to Fig. 1). This route to obtain ceramic membrane is referred to as sol-gel technique from destabilization of colloidal solutions (DCS). Another kind of sol-gel technique based on polymerization of molecular units (PMU) has been described elsewhere ${ }^{[2]}$. Sol-gel method for producing membrane with extremely small pore size has attracted immense interest in the past ${ }^{[3]}$ and it continues to be in the present and future.

The sol gel technique is attractive for application on a porous filter support or in other words, composite membrane preparation. In the processes, a sol is first prepared using an organo-metallic oxide as a precursor or starting material. This is followed by addition of viscosity modifier and binders. Normally, the sol is stabilized to avoid significant particle aggregation from taking place. This is done by addition of some threshold amount of acid and heat treatment for sufficient period of time. The acid maintains a stable dispersion by producing similar electric charges as the particles that causes the particles to repel each other. Later, the thickened sol is deposited or coated as a layer on the support by dip or spin coating, after which it is dried under controlled environment to form a gel. In the final process, the membrane is calcined and sintered before the composite ceramic membrane is obtained. 


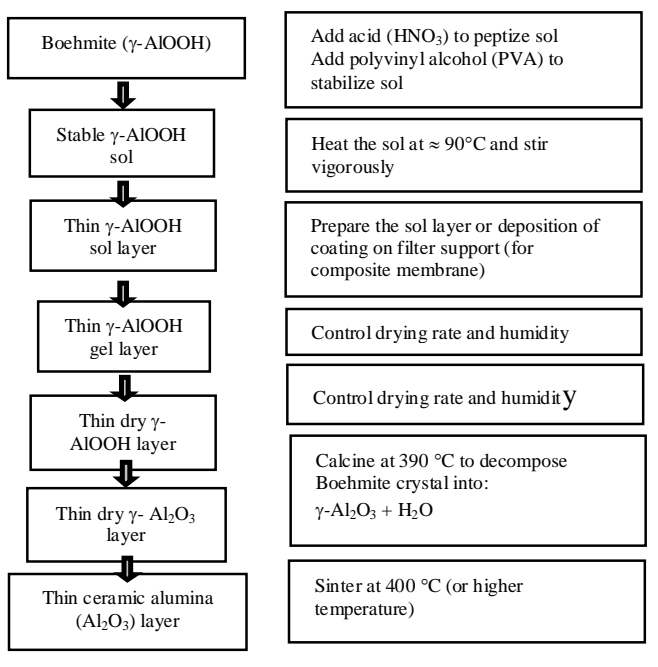

Fig. $1 \gamma$-alumina membrane preparation using sol gel technique

Most popular oxide materials that have been made into micro-porous membranes via sol-gel route are alumina, zirconia, titania, silica and porous glass. They are derived from the associated alkoxides. Alumina, for example, is derived from aluminum sec-butoxide. More materials have been studied to produce membranes by sol-gel processing. Burggraaf et al., ${ }^{[4]}$ for instance, have successfully obtained ceria membranes with a mean pore diameter of $2 \mathrm{~nm}$. Hackley and Anderson, ${ }^{[5]}$ have investigated ferric oxide ceramic membranes, which could yield pore diameter of about less than $3.4 \mathrm{~nm}$ to $10 \mathrm{~nm}$. Combination or addition of inert components such as zirconia ${ }^{[6]}$ and lanthanum during ceramic membrane preparation is also possible. In fact, the application of supported zirconia membrane in aqueous filtration has been made successful ${ }^{[7]}$. The zirconia membrane was tested in a cross-flow ultrafiltration of soybean oil/hexane solution and the rejection of this solution was found to achieve $37 \%$ higher than without zirconia.

\section{FACTORS AFFECTING MEMBRANE DEVELOPMENT}

\subsection{Addition of Water}

In the preparation of ceramic membranes, the alkoxide must be hydrolyzed in water heated at about $80-90^{\circ} \mathrm{C}$ for minimum of 18 hours. The correct amount of water is important for the hydrolysis and condensation. Water influences the viscosity of the sols and gelation time. Excessive use of water increases the drying time of the sol to form gel. For the case of alumina membranes, Huang et al., ${ }^{[8]}$ reported that the gelatinized period increased when the molar ratio of $\mathrm{H}_{2} \mathrm{O}$ to $\mathrm{Al}^{3+}$ was increased. The viscosity however, decreased with increasing amount of water as shown in Table 1.
Table 1 Sol's viscosity at $84^{\circ} \mathrm{C}$ using different $\mathrm{H}_{2} \mathrm{O} / \mathrm{Al}^{3+}$ molar ratio. ${ }^{[8]}$

\begin{tabular}{ccc}
$\begin{array}{c}\text { Molar ratio } \\
\mathrm{H}_{2} \mathrm{O} / \mathrm{Al}^{3+}\end{array}$ & Viscosity (x 10 $0^{-3}$ Pa.s) & Appearance of sol \\
\hline $50: 1$ & - & Too thick \\
$100: 1$ & 2.370 & Clear sol \\
$125: 1$ & 1.805 & Clear sol \\
$150: 1$ & 1.494 & Clear sol \\
\hline
\end{tabular}

Cho et al., ${ }^{[9]}$ claimed that low viscosity sol as a result of excessive use of water would not form gel layer on a porous support. Naturally, diluted sol would be absorbed by the support. If the sol concentration is too high, however, thick gel layer could be formed and this would produce crack membranes or membranes with peeling-off layer during drying.

\subsection{Addition of Acid}

In essence, acid is added for stabilization and peptization of sol during gelation process. The acid added to an uncharged particle system peptizes the larger particles, producing smaller ones, which become positively charged through proton adsorption. Table 2 shows the effect of acid addition on sol formation from the work of Yoldas ${ }^{[10]}$ in which alkoxide used was $\mathrm{Al}(\mathrm{OBu})_{3}$ and the acid was $\mathrm{HCl}$. At least 0.03 mole of acid per mole of alkoxide (or hydroxide) had to be added in order to peptize the system to a clear sol. complete peptization could not be attained for molar ratio below 0.03 .

Table 2 Effect of acid concentration on the sol formation. ${ }^{[10]}$

\begin{tabular}{lll}
\hline Sample & $\begin{array}{l}\text { Molar ratio } \\
\text { Acid/hydroxide }\end{array}$ & $\begin{array}{l}\text { Sol condition after } 4 \\
\text { days heated at } 95^{\circ} \mathrm{C}\end{array}$ \\
\hline 1 & 0.0154 & Unpeptized (Cloudy sol) \\
2 & 0.0231 & Unpeptized (Cloudy sol) \\
3 & 0.0384 & Clear sol \\
4 & 0.0467 & Clear sol \\
5 & 0.0537 & Clear sol \\
6 & 0.0691 & Clear sol \\
7 & 0.1075 & Clear sol \\
8 & 0.1540 & Clear sol \\
9 & 0.2070 & Clear sol \\
10 & 0.2460 & Clear sol \\
\hline
\end{tabular}

Not all types of acid can be used for peptization and hence the choice of acid used for peptization is extremely important. There are two general requirements for the selection of acids. In preparing alumina sol for instance, the anion of the acids should be non-complexing or at least very weakly complexing with the aluminum ions. The acid should also be sufficiently strong to produce the necessary charge effect in relatively small quantities with respect to the aluminum concentration ${ }^{[10]}$. Table 3 lists the peptizing effect of various acids on the sol formation. 
Table 3 Effect of different types of acids on the sol formation. ${ }^{[10]}$

\begin{tabular}{lll}
\hline Type of acid & & $\begin{array}{l}\text { Sol condition } \\
\text { after } \\
7 \text { days heat } \\
\text { treatment }\end{array}$ \\
& & Clear sol \\
Nitric & $\left(\mathrm{HNO}_{3}\right)$ & Clear sol \\
Hydrochloric & $(\mathrm{HCl})$ & Clear sol \\
Perchloric & $(\mathrm{HClO})$ & Unpeptized \\
Hydrofluoric & $\left(\mathrm{HF}_{4}\right)$ & Unpeptized \\
Iodic & $\left(\mathrm{HIO}_{4}\right)$ & Unpeptized \\
Sulfuric & $\left(\mathrm{H}_{2} \mathrm{SO}_{4}\right)$ & Unpeptized \\
Phosphoric & $\left(\mathrm{H}_{3} \mathrm{PO}_{4}\right)$ & Unpeptized \\
Boric & $\left(\mathrm{H}_{3} \mathrm{BO}_{4}\right)$ & Clear sol \\
Acetic & $\left(\mathrm{CH}_{3} \mathrm{COOH}\right)$ & Clear sol \\
Trichloroacetic & $\left(\mathrm{CCl}_{3} \mathrm{COOH}\right)$ & Clear sol to \\
Monochloroacetic & $\left(\mathrm{CH}_{2} \mathrm{ClCOOH}\right)$ & cloudy \\
Formic & $(\mathrm{HCOOH})$ & Clear sol to \\
Oxalic & $\left(\mathrm{H}_{2} \mathrm{C}_{2} \mathrm{O}_{4} \cdot 2 \mathrm{H}_{2} \mathrm{O}\right)$ & cloudy \\
Phthalic & $\left(\mathrm{C}_{8} \mathrm{H}_{4} \mathrm{O}_{3}\right)$ & Unpeptized \\
Citric & $\left(\mathrm{H}_{3} \mathrm{C}_{6} \mathrm{H}_{5} \mathrm{O}_{7} . \mathrm{H}_{2} \mathrm{O}\right)$ & Unpeptized \\
Carbolic & $\left(\mathrm{C}_{6} \mathrm{H}_{5} \mathrm{OH}\right)$ & Unpeptized \\
& & Unpeptized \\
\hline
\end{tabular}

When acid concentration is properly controlled, acid can be used as a mean to adjust the pore size of membranes according to the desired level. Leenaars et al., ${ }^{[11]}$ demonstrated that the pore size of the alumina membrane they developed decreased with increasing molar ratio of acid to alkoxide. Yoldas ${ }^{[12]}$ found that the pore diameter increased slightly with increasing acid to sol ratio when the ratio was below 0.05-0.06 and it reached a maximum level near the ratio. Yoldas ${ }^{[12]}$ also showed that the pore radius of alumina membrane was almost constant for molar ratio of acid/hydroxide between 1:0.03-0.10. For molar acid larger than 0.10, the pore radius was gradually decreased. However, the membrane produced using greater than 0.10 mole of acid formed cracks.

In the work of Leenars et al., ${ }^{[11]}$ pore size reduction from 2.8 to $2.5 \mathrm{~nm}$ was observed when the acid concentration was increased from 0.05 to $0.11 \mathrm{~mol}$ of $\mathrm{HClO}_{4}$ per mol of $\gamma-\mathrm{AlOOH}$, as illustrated in Table 4 .

Table 4 Pore size against the acid quantity in the sol. ${ }^{[11]}$

\begin{tabular}{llll}
\hline $\begin{array}{l}\text { Molar ratio } \\
\mathrm{HClO}_{4} / \gamma-\mathrm{AlOOH}\end{array}$ & \multicolumn{2}{c}{ Modal pore size $(\mathrm{nm})$} & $\begin{array}{l}\text { Porosity } \\
(\%)\end{array}$ \\
\hline \multicolumn{3}{c}{ Cylindrical shape } & Slit shape \\
0.05 & 4.1 & 2.8 & 49 \\
0.07 & 3.8 & 2.6 & 44 \\
0.09 & 3.7 & 2.6 & 42 \\
0.11 & 3.5 & 2.5 & 38 \\
\hline
\end{tabular}

\subsection{Addition of Binders and Plasticizers}

Membrane may crack during sol gel process for a number of reasons. Membrane layer that is too thick, incorrect molar composition of the alkoxide, water, and acid during sol preparation, are actually few of the reasons for producing crack membrane. Commonly, binders are introduced to add strength to the membrane and avoid crack from forming in membrane layer. Examples of organic binders used in ceramic processing are polyvinyl alcohol (PVA), polyvinyl acetate and cellulose compounds such as methyl cellulose and hydroxyethyl cellulose. The purposes of organic binder are to avoid particle aggregation, permit adjusting of viscosity and increase the mechanical strength of the material by reducing its stiffness and brittleness and maintaining its shape until it is sintered.

Organic binders are burnt out at a temperature above approximately $300^{\circ} \mathrm{C}^{[1]}$ and they should burn gradually without leaving ashes or tar. PVA and cellulose compounds that serve this purpose ${ }^{[2]}$ can be exploited to control the average pore size, pore size distribution and overall porosity in the membrane material. For production of dense structure of an essentially void free sintered product with small grain sizes for instance, low PVA content should be used ${ }^{[13]}$. Yang et al., ${ }^{[14]}$ have shown that the range of pore size distributions increase with increasing PVA content. Das and Maiti ${ }^{[15]}$ reported that higher binder content promotes agglomeration of the ceramic particles, which on firing leads to wider pore size distribution and formation of closed pores. Introduction of binder also help in the production of composite membrane. As Bae et al., ${ }^{[16]}$ have discovered, an organic binder such as polyvinyl alcohol (PVA) was actually necessary for depositing $\mathrm{Al}_{2} \mathrm{O}_{3}-\mathrm{TiO}_{2}$ coating on porous supports to enable successful production of composite thin membrane.

Plastisicer is a liquid oligomer, structurally similar to that of binder. It is normally used with binder to penetrate in the middle of the binder molecules and lubricate them, allowing them to slide against each other and take up the strain to prevent formation of crack in the membrane layer. Examples of plasticizers commonly used are water, polyethylene glycol, ethylene glycol, diethylene glycol, tetraethylene glycol, glycerine, dimethyl phthalate, dibuthyl phthalate, Octyl phthalate, benzyl butyl phthalate and diethyloxalate ${ }^{[17]}$. Though effective in preventing formation of crack, it should be used with caution because addition of plastisicer such as polyethylene glycol can actually increase the surface area, pore volume and pore diameter of the final ceramic membrane as reported in the work of Lambert and Gonzalez ${ }^{[18]}$.

\subsection{Membrane Thickness}

Thick membrane can give rise to peeling and crack layer during drying and calcination. It was discovered that membrane thickness between 1 and 5-7 $\mu \mathrm{m}$ prevented the formation of crack layers and pinholes ${ }^{[19]}$. When membranes surpass this range of thickness, crack tends to form. This phenomenon was observed in the work of Leenaars et al., ${ }^{[1]}$ in which membrane having thickness larger than $20 \mu \mathrm{m}$ was used. Production of thick layer of film can be avoided if a dilute sol of approximately $0.52 \mathrm{~mol} \mathrm{Al} /$ litre, is used ${ }^{[20]}$. Sol cannot be too diluted however, because it can cause absorption of the sol by support and thus, no gel layer is formed. 
For production of desirable coating thickness, the dipping time should be about 3 seconds ${ }^{[21]}$. Greater than the recommended dipping time may result in undesirably thick coating that produces crack, while dipping time that is too short may result in coating that is too thin to hold the support.

In another experimental work, Huang et al., ${ }^{[8]}$ have demonstrated that crack free membrane having thickness between $0.1-200 \mu \mathrm{m}$ could be produced successfully if sols were atomized by a high velocity gas and sprayed onto the support. Crack free membrane with thickness greater than $200 \mu \mathrm{m}$ could also be produced provided that it was dried at controlled rate.

\subsection{Drying Rate}

Drying, which is described as the elimination of water or solvent from the pores of a solid is a routine procedure to obtain crystallized compounds. The product obtained from ordinary drying is a dry or zerogel in which, it does not decompose or lose matter through sintering. During drying operation, the pore volumes decrease while the density increases as the dimensions of pores become smaller ${ }^{[22]}$. In practice, there are two stages of drying during membrane development from sol gel technique. In the first stage of drying, water exposed to or near the atmosphere is evaporated. Water lies in the pores then migrates to the surface to replace the evaporating water from the outer surface of the gel layer. The removal of water from inner to outer gel continues progressively until the moisture content diminishes. This causes the gel layer to shrink and eventually allow particles in the gel to come in contact with each other. In the second stage of drying, further drying of the gel will remove immobile or residual water. Ideally, there should be no reduction of pore volume during the second stage of drying.

During drying, warping or deformation of membrane structure may be observed. This is due to the rate of evaporation that is not even. Moisture normally evaporates from the top surface first followed by the surface under it. This causes the top surface to shrink faster than the other parts of membrane, and hence result in membrane that may curl upward or sometimes roll to form a shape like a tube. Uneven drying is a common cause of crack membrane. In order to prevent uneven drying from taking place, drying of sol should be performed at a slow and steady pace and constantly high humidity.

\subsection{Sintering Temperature}

The final physical properties including density, porosity distribution, grain size, morphology and microstructures of ceramic membrane are dependent upon the choice of sintering temperature. Sintering process is also performed to obtain firm coalescence between particles and particles with the support, and a well-determined membrane structure with good mechanical resistance. Depending upon the type of ceramic membrane, the sintering temperature could be as low as $250^{\circ} \mathrm{C}$ to as high as $1700^{\circ} \mathrm{C}$. The highest temperature in the sintering profile is used to obtain the desired level of porosity. The porosity, which is a result of water driven off from the pores and decomposition of organic materials, may decrease or increase as the temperature is raised depending upon the compositions and minerals that are present in the ceramic ${ }^{[23]}$.

In general, the porosity level increases as the temperature increases but the mechanical strength falls significantly. Highly porous membrane as a result of extremely high sintering temperature suffers fragmentation under vibration conditions. This is further exacerbated when membrane material is not free from impurities such as glass and iron. Above about $900^{\circ} \mathrm{C}$, glass in the alumina membrane for instance, becomes fluid and allows deformation and fracture of bridges between alumina grains. While that with iron content degrades its strength at about $1300^{\circ} \mathrm{C}^{[24]}$. Leenars et al., ${ }^{[11]}$ have shown that the pore size of alumina membrane increases with increasing temperature. The increase was more obvious for thick membrane ${ }^{[25]}$. In another similar work, Morell ${ }^{[24]}$ discovered that the porosity and the crystallite size of the membrane exhibit no systematic change during heat treatment in the range of $400-800^{\circ} \mathrm{C}$.

John ${ }^{[26]}$ emphasizes that under firing of a ceramic can leave the material structurally weak and oversized. On the other hand, over firing can result in excessive grain growth, undesirable pore coalescence, and bloating. Larbot et al. ${ }^{[2]}$ claimed that the pore size of alumina membrane could be controlled by varying the sintering temperature. They presented the evolution of pore diameters as a function of sintering temperature in a graphical form (Fig. 2) and concluded that the pore diameter increased as temperature increased during thermal treatment.

Fig. 2 Pore diameters plotted against temperature. ${ }^{[2]}$

The relationship between pore and sintering temperature of the 3 respective ceramic membrane materials (titania, alumina, and zirconia) is illustrated in Fig. $3^{[27]}$. From the graph, it appears that the pore size of alumina membrane is more stable at higher temperature than the other ceramic membranes and it only increases considerably after sintering temperature reaches beyond $1000^{\circ} \mathrm{C}$.

In another experimental work, the pore size of alumina membrane was found to increase from 3.7 to $78 \mathrm{~nm}$ when temperature was increased from 200 to $1000{ }^{\circ} \mathrm{C}$ as shown in Table 5. ${ }^{[11]}$ 
Fig. 3 Pore diameters as a function of temperature. ${ }^{[27]}$

Table 5 Membrane pores as a function of sintering temperature. ${ }^{[11]}$

\begin{tabular}{ccccc}
\hline $\begin{array}{c}\text { Temperature } \\
\left({ }^{\circ} \mathrm{C}\right)\end{array}$ & $\begin{array}{c}\text { BET } \\
\text { surface } \\
\text { area } \\
\left(\mathrm{m}^{2} \mathrm{~g}^{-1}\right)\end{array}$ & $\begin{array}{c}\text { Modal pore size } \\
(\mathrm{nm})\end{array}$ & $\begin{array}{c}\text { Porosity } \\
(\%)\end{array}$ \\
\hline & & Cylindrical & Slit & \\
200 & $315 \pm 2$ & 3.7 & 2.5 & 41 \\
400 & $301 \pm 7$ & 4.0 & 2.7 & 53 \\
500 & $240 \pm 1$ & 4.9 & 3.2 & 54 \\
600 & $209 \pm 1$ & 5.5 & 3.5 & 55 \\
700 & $181 \pm 1$ & 5.9 & 3.7 & 53 \\
800 & $154 \pm 2$ & 7.9 & 4.8 & 55 \\
900 & $99 \pm 2$ & 8.9 & 5.4 & 48 \\
1000 & $15 \pm 3$ & 78 & 39 & 41 \\
\hline
\end{tabular}

The increase of temperature does not only affect or increase the pore size of ceramic membranes but also decrease the BET surface area. The change of membrane phase also takes place at higher temperature as described in the work of Leenaars et al., ${ }^{[1]}$. In this work, the boehmite sol was changed to $\gamma$-alumina and later $\alpha$-alumina as temperature increased from 200 to $1000^{\circ} \mathrm{C}$ illustrated in Table 6.

Table 6 Phase change of alumina membrane at different sintering temperature. ${ }^{[11]}$

\begin{tabular}{cccc}
\hline Temperature $\left({ }^{\circ} \mathrm{C}\right)$ & $\begin{array}{c}\text { Pore size }(\mathrm{nm}) \\
(\text { Cylindrical })\end{array}$ & $\begin{array}{c}\text { Pore size } \\
(\mathrm{nm}) \\
(\mathrm{Slit})\end{array}$ & $\begin{array}{c}\text { Phase } \\
\text { change }\end{array}$ \\
\hline 200 & 3.7 & 2.5 & $\gamma-\mathrm{AlOOH}$ \\
400 & 4.0 & 2.7 & $\gamma-\mathrm{Al}_{2} \mathrm{O}_{3}$ \\
500 & 4.9 & 3.2 & $\gamma-\mathrm{Al}_{2} \mathrm{O}_{3}$ \\
600 & 5.5 & 3.5 & $\gamma-\mathrm{Al}_{2} \mathrm{O}_{3}$ \\
700 & 5.9 & 3.7 & $\gamma-\mathrm{Al}_{2} \mathrm{O}_{3}$ \\
800 & 7.9 & 4.8 & $\gamma-\mathrm{Al}_{2} \mathrm{O}_{3}$ \\
900 & 8.9 & 5.4 & $\gamma-\mathrm{Al}_{2} \mathrm{O}_{3}$ \\
1000 & 78.0 & 39.0 & $\alpha-\mathrm{Al}_{2} \mathrm{O}_{3}$ \\
\hline
\end{tabular}

\section{CONCLUSION}

In order to obtain ceramic membrane with the desired characteristics and free from defect such as crack layer from the sol-gel method, factors such as the correct amount of acid, water, and binder, appropriate membrane thickness, proper control of drying rate, and appropriate temperature profile described earlier should be taken into account. According to previous works, crack formation can be avoided if sol is not too viscous and membrane layer is as thin as possible. The importance of correct amount of acid in the sol and proper drying condition of sol in preventing the formation of crack layer is also indisputable. A proper amount of acid addition can control the level of membrane pore size. Equally importance is the sintering temperature. A proper selection of sintering profile can tailor the size of pore and membrane porosity according to the desired level.

\section{ACKNOWLEDGEMENT}

The authors acknowledge the research grant provided by University Sains Malaysia Penang that has enabled the production of this article.

\section{REFERENCES}

[1] H. P Hsieh, Inorganic membrane for separation and reaction, Elsevier, pp. 28-59, 1996.

[2] A. Larbot, J. P. Farbe, C. Guizard and L. Cot, "Inorganic Membranes Obtained by Sol-Gel Techniques", J. Memb. Sci., Vol. 39, pp. 203-212, 1988.

[3] D. Segal, Chemistry of Solid State Materials, Chemical Syntesis of Advance Ceramic Materials, Cambridge University Press, New York, USA, 1989.

[4] A. J Burggraaf, K. Keizer and B. A. Van Hassel, Solid State Ionic, Vol. 32/33, pp. 771, 1989.

[5] V. A. Hackley and M. A. Anderson, J. Memb. Sci., Vol. 70, pp. 41, 1992.

[6] C. Lijzenga, K. Keizer, M. H. B. J. Huis in't Veld, A. J. Burggraaf and M. A. Anderson, "Zirconia-Coated Gamma-alumina Membrane Toplayers”, Key Engr. Mat., Vol. 62\& 61, pp. 383-386, 1991.

[7] J. C. S. Wu and L. C. Cheng, "An improved synthesis of ultrafiltration zirconia membranes via the sol-gel route using alkoxide precursor", J. Memb. Sci., Vol. 167, pp. 253-261, 2000

[8] X. R Huang, G. L. Meng, Z. T. Huang and J. M. Geng, "Preparation of Unsupported Alumina Membrane by SolGel Technique", J. Memb. Sci., Vol. 133, pp. 145-150, 1997.

[9] Y. K Cho, H.K Woo and K.H Lee, "Separation of CO2 by Modified $\square-\mathrm{Al} 2 \mathrm{O} 3$ Membranes a High temperature", J. Memb. Sci., Vol. 104, pp. 219-230, 1995.

[10] B. E. Yoldas, "Alumina Sol Preparation From Alkoxides", Ceramic Bulletin, Vol. 54, pp. 289-291, 1975a.

[11] A. F. M. Leenaars, K. Keizer and A. J. Burggraaf, "The Preparation and Characterization of Alumina Membranes with ultra-Fine Pores", J. Memb. Sci., Vol. 19, pp. 10771088, 1984.

[12] B. E. Yoldas, "Alumina Gels that Form Porous Transparent A12O3”, J. Memb. Sci., Vol. 10, pp. 18561861, 1975b. 
[13] R. Mishra and K. J. Rao, "Thermal and Morphological Studies of Binary and Ternary Composites of Poly (Vinyl Alcohol) with Alumina and Zirconia, Ceramics Intern., Vol. 26, pp. 371-378, 2000.

[14] W. P. Yang, S. S. Shyu, E. S. Lee and A. C. Chao, "Effects of Poly (Vinyl Alcohol) Content and Calcination Temperature on the Characteristic of Unsupported Alumina Membrane", J. Sep. Sc. Tech., Vol. 31, pp. 1327-1343, 1996.

[15] A. C. Pierre, "Porous Sol-Gel Ceramics", Ceram. Intern., Vol. 23, pp. 229-238, 1997.

[16] D. S. Bae, D. S. Cheong, K. S. Han, S. H. Choi, "Fabrication and microstructure of $\mathrm{Al} 2 \mathrm{O} 2-\mathrm{TiO} 2$ composite membranes with ultrfine pores," Ceramic Intern., Vol. 24 , pp. 25-30, 1998.

[17] R. Moreno, "The Role of Slip Additives in Tape Casting Technology: Part II - Binders and Plasticizer", Am. Ceram. Soc. Bul., Vol. 71, pp. 147-165, 1992.

[18] C. K. Lambert and R. D. Gonzalez, "Effect of binder addition on the properties of unsupported $\gamma$ - Al2O3 membranes," J. Materials. Letters, 38, Vol. 2, pp. 1451491999.

[19] K. Keizer, R. J. R. Uhlhorn, R. J. Van Varen, A. J. Burggraaf; "Gas separation mechanisms in microporous modified $\gamma$-Al2O3 membranes," J. Memb. Sci., Vol. 39, pp. 285-300, 1988.

[20] T. Okubo, M. Watanabe, K. Kusakabe, S. Morooka, "Preparation of $\gamma$-Alumina thin membrane by sol-gel technique and its characterization by gas permeation," J. Memb. Sci., Vol. 25, pp. 4822-4827, 1990.

[21] A. F. M. Leenaars and A. J. Burggraaf, "The preparation and characterization of alumina membranes with ultrafine pores," J. Col. Interf. Sc., 105, Vol. 1, pp. 27-40, 1985.

[22] J. F. Le Page, Applied Heterogeneous Catalysis, Gulf Publishing Company, Texas, 1987.

[23] R.W Grimshaw, The Chemistry and Physics of Clays and Allied Ceramics Materials, Ernest Benn Ltd., London, Vol. 4th ed., pp. 814, 1971.

[24] R. Morrell, Handbook of properties of technical \& engineering ceramics, part 2 data reviews, section 1 highalumina ceramics, National physical laboratory, HMSO publication center, London, 1987.

[25] P. Wong, P. Huang, N. P. Xu, J. Shi and Y. S. Lim, "Effects of Sintering on Properties of Alumina Microfiltration membranes", J. Memb. Sc., Vol. 155, pp. 309-314, 1999.

[26] A. M John, Advance in Ceramic: Forming of Ceramic, Am. Ceram. Soc., Vol. 9, pp. 29, 1984.

[27] A. C. Pierre, "Porous Sol-Gel Ceramics", Ceram. Intern., Vol. 23, pp. 229-238, 1997.

\section{BIOGRAPHY}

Mohd Roslee Othman was born on July 4, 1970 in Klang, Selangor, Malaysia. He received his Bachelor and Master of Science Degrees from University of Missouri-Rolla, Missouri, USA in 1994 and 1997 respectively. $\mathrm{He}$ is currently pursuing his Doctoral degree in Chemical Engineering (Membrane separation) at Universiti Sains Malaysia.

Dr Hilmi Mukhtar Graduated in Chemical Engineering from University of Wales Swansea, UK. And obtained MSc in Chemical Engineering from the same University. He Obtained his $\mathrm{PhD}$ in Membrane Technology in 1995 and a Lecturer in USM from 1995 until today. Starting from April 2001, He is a lecturer in University of Technology Petronas. He's area of research is membrane development for inorganic membrane in particular, membrane modeling for Reverse Osmosis and nanofiltration membranes and membrane applications especially in wastewater control and downstream processing. Other area includes in solvent extraction process in recycling of waste oil. 